\title{
Pengembangan Aplikasi Mobile Augmented Reality sebagai Media Pembelajaran Biologi Materi Sel
}

\author{
Julian Sahertian ${ }^{1}$, Risa Helilintar ${ }^{2}$ \\ 1) 2) Teknik Informatika, Fakultas Teknik, Universitas Nusantara PGRI Kediri \\ Kampus 2, Mojoroto Gg 1 No. 6, Kediri \\ 1) E-mail : juliansahertian@unpkediri.ac.id \\ 2)E-mail : risahelilintar@unpkediri.ac.id
}

\begin{abstract}
Abstrak - Pada penelitian ini dikaji penerapan teknologi augmented reality untuk membuat aplikasi mobile media pembelajaran pada pokok bahasan sel tingkat SMA. Materi yang diambil sebagai konten aplikasi media pembelajaran adalah pada standar kompetensi memahami struktur dan fungsi sel sebagai unit terkecil kehidupan untuk siswa SMA. Aplikasi media pembelajaran yang dikembangkan hanya bersifat suplemen pembelajaran diluar kegiatan pembelajaran di kelas. Penelitian yang dilakukan mengunakan metode penelitian dan pengembangan ( $\& \& D)$ sedangkan model pengembangan media pembelajaran yang digunakan adalah model pengembangan aplikasi Waterfall. Metode pengembangan aplikasi ini dipilih karena proses pengembangan media yang dilakukan memiliki waktu yang efisien karena revisi aplikasi hanya dilakukan di akhir proses pengembangan. Penelitian dilakukan secara kuantitatif yang didapat dari hasil angket yang disebarkan kepada pengguna aplikasi media pembelajaran yaitu siswa tingkat SMA. Hasil penilaian angket kevalidan media pembelajaran yang diisi oleh siswa menunjukkan bahwa aplikasi media pembelajaran mobile augmented reality pada pokok bahasan sel ini memiliki persentase kevalidan sebesar 91\% sehingga dapat dikatakan bahwa aplikasi ini valid dan layak digunakan sebagai media pembelajaran berdasarkan kriteria kevalidan media dari Akbar dan Sriwiyana (2010).
\end{abstract}

Kata Kunci: Augmented Reality, Media Pembelajaran, Mobile, R\&D, Waterfall

\section{PENDAHULUAN}

Media pembelajaran berkembang sangat pesat mengikuti perkembangan teknologi yang ada saat ini. Berdasarkan dari perkembangan teknologi yang ada saat ini media pembelajaran dikelompokkan ke dalam empat bagian, yaitu: (1) Media hasil teknologi cetak, (2) Media hasil teknologi audio-visual, (3) Media hasil teknologi berbasis komputer, (4) Media hasil gabungan teknologi cetak dan komputer (Arsyad, 2009:29). Khusus untuk media pembelajaran hasil gabungan teknologi cetak dan komputer terdapat teknologi yang dinamakan augmented reality. Augmented reality adalah sebuah teknologi yang akan menempatkan suatu gambar virtual dari grafis komputer pada dunia nyata atau dengan kata lain penggabungan antara dunia nyata dengan dunia virtual. Sehingga apabila diimplementasikan dalam bentuk media pembelajaran, informasi yang diperoleh lebih kaya dan lebih menarik dibanding media pembelajaran cetak ataupun digital biasa.

Penelitian tentang pemanfaatan teknologi augmented reality untuk media pembelajaran telah banyak dilakukan, antara lain oleh Kaufmann (2001). Pada penelitian tersebut dikaji mengenai pemanfaatan teknologi augmented reality dalam dunia pendidikan yaitu pada pelajaran geometri atau bangun ruang. Hasil dari penelitian tersebut menunjukkan bahwa kelebihan dari media pembelajaran berbasis augmented reality adalah mudah dan murah dalam pengembangannya dibandingkan dengan media lain yang membutuhkan tenaga dan biaya tambahan dalam pengadaan perangkat kerasnya.

Salah satu mata pelajaran yang cocok untuk penerapan teknologi ini adalah matapelajaran biologi yaitu pada pengenalan sel. Karena untuk menerangkan materi sel masih menggunakan gambar yang kurang merepresentasikan bentuk sebenarnya dari sel itu sendiri serta tampilannya yang kurang begitu menarik. Selain itu sel merupakan unit terkecil dari makhluk hidup yang tidak bisa dilihat manusia dengan mata telanjang. Sehingga dengan menggunakan teknologi augmented reality ini sel dapat dimodelkan dalam bentuk tiga dimensi yang lebih realistis dan siswa dapat melihat detail dari bagian-bagian sel tersebut.

Pada penelitian ini akan dikaji penerapan teknologi augmented reality untuk membuat aplikasi mobile sebagai media pembelajaran biologi tingkat SMA. Penerapan teknologi augmented reality pada perangkat mobile dipilih karena berdasarkan dari pegamatan yang dilakukan para siswa sekarang sudah memiliki perangkat mobile berupa smartphone yang bisa digunakan untuk berbagai keperluan sehingga dengan adanya aplikasi mobile augmented reality yang akan dikembangkan ini dapat memudahkan siswa dalam belajar. Materi yang menjadi bahan kajian adalah pada standar kompetensi memahami struktur dan fungsi sel sebagai unit terkecil kehidupan untuk siswa SMA kelas XI semester 1. Materi tersebut diambil karena pemodelan sel pada materi tersebut dalam melakukan pengamatan pada obyek sel perlu menggunakan peralatan tambahan yaitu mikroskop 
yang memerlukan biaya yang tidak murah dan juga objek sel yang dilihat mengunakan mikroskop hanya menunjukkan bentuk fisis dan tidak dilengkapi dengan keterangan-keterangan teroritis.

\section{TINJAUAN PUSTAKA}

Bagian ini menjelaskan tentang tinjauan pustaka dalam penelitian ini mulai dari kajian penelitian sebelumnya dan teori-teori pendukung.

\subsection{Kajian Penelitian Sebelumnya}

Penerapan teknologi augmented reality saat ini sebenarnya sudah cukup luas, termasuk dalam bidang pendidikan. Mark Billinghurst (2002) berpendapat bahwa pemanfaatan teknologi augmented reality dalam dunia pendidikan masih terus dikembangkan sampai saat ini. Karena tidak seperti teknologi komputasi pada umumnya, Antar muka augmented reality mampu mengintegrasikan pengguna, obyek virtual, dan lingkungan nyata. Serta dalam penerapannya pada lingkungan sekolah perlu adanya kolaborasi antara guru atau pengajar dengan peneliti di lapangan untuk mengetahui kecocokan penerapan media augmented reality dengan kurikulum yang ada di sekolah tersebut.

Pendapat tersebut sejalan dengan kesimpulan Hannes Kaufmann (2001) bahwa seiring dengan kemajuan dalam perkembangan konsep pedagogis, aplikasi dan teknologi, dan penurunan biaya perangkat keras, penggunaan skala kecil teknologi augmented reality untuk lembaga pendidikan menjadi sangat memungkinkan dalam dekade ini (dengan asumsi pembangunan berkelanjutan di tingkat yang sama). Namun demikian, potensi teknologi ini membutuhkan perhatian yang seksama agar benar-benar dapat dimanfaatkan untuk meningkatkan keberhasilan pendidikan.

Dari beberapa pendapat para ahli tersebut dapat disimpulkan bahwa teknologi augmented reality sangat berpotensi untuk diterapkan pada dunia pendidikan. Pada penelitian ini akan dikaji salah satu pemanfaatan teknologi augmented reality dalam dunia pendidikan yaitu melalui pengembangan suatu aplikasi mobile sebagai media pembelajaran berbasis augmented reality.

\subsection{Media Pembelajaran}

Kata media berasal dari bahasa latin dan merupakan bentuk jamak dari kata medium yang secara harfiah berarti perantara atau pengantar. (Sadiman: 2009, 6) mengungkapkan media adalah perantara atau pengantar pesan dari pengirim ke penerima pesan. Sadiman (2009:7) juga menyimpulkan bahwa media adalah segala sesuatu yang digunakan untuk menyalurkan pesan dari pengirim ke penerima sehingga dapat merangsang fikiran, perasaan, perhatian dan minat serta perhatian siswa sedemikian rupa sehingga proses belajar terjadi.

Media pembelajaran yang baik adalah suatu media yang mampu membuat siswa menjadi lebih paham tentang materi yang disampaikan oleh guru. Untuk itu pada penelitian ini dikaji pengembangan media pembelajaran menggunakan teknologi augmented reality. Media pembelajaran berbasis augmented reality akan memberikan pengalaman tersendiri (personal experience) kepada siswa dengan menghadirkan obyek virtual ke dunia nyata, sehingga melalui pengalaman tersebut informasi yang disampikan melalui teknologi augmented reality akan selalu teringat/terkesan di memori siswa. Dengan kata lain pelajaran yang disampaikan dapat dipahami dan selalu teringat oleh siswa.

\subsection{Augmented Reality}

Menurut definisi Ronald T. Azuma (1997: 1) ada tiga prinsip dari augmented reality. Pertama, augmented reality merupakan penggabungan dunia nyata dan virtual. Kedua, berjalan secara interaktif dalam waktu nyata (realtime), dan ketiga terdapat integrasi antarbenda dalam tiga dimensi, yaitu benda maya terintegrasi dalam dunia nyata. Dalam perkembangannya saat ini augmented reality tidak hanya bersifat visual saja, tapi sudah dapat diaplikasikan untuk semua indera, termasuk pendengaran, sentuhan, dan penciuman. Selain digunakan dalam bidang-bidang seperti kesehatan, militer, industri manufaktur, augmented reality juga telah diaplikasikan dalam perangkat-perangkat yang digunakan orang banyak, seperti pada perangkat mobile.

Cara kerja augmented reality adalah sebagai berikut. Video atau kamera yang digunakan pada aplikasi augmented reality menangkap gambar marker yang lebih dulu diidentifikasi, setelah itu dilakukan perhitungan posisi dan orientasi marker. Hasil perhitungan tersebut dimasukkan ke dalam matriks. Matriks ini kemudian dipakai untuk menentukan virtual kamera relatif terhadap marker. Library 3D digunakan untuk menggambar obyek virtual berdasarkan matriks $3 \times 4$ yang berisi koordinat lingkungan nyata relatif terhadap marker. Untuk lebih jelasnya dapat dilihat pada Gambar 1.

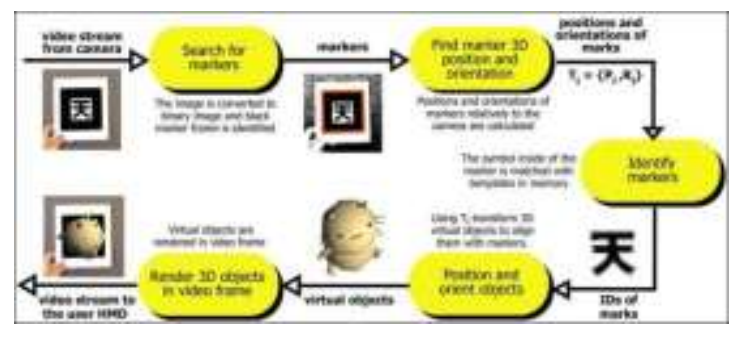

Gambar 1. Blok diagram augmented reality (sumber: www.hitl.washington.edu)

\section{METODE PENELITIAN}

Penelitian yang dilakukan merupakan jenis penelitian dan pengembangan (R\&D) seperti dikemukakan oleh Sugiyono (2009). Sedangkan metode pengembangan perangkat lunak yang 
digunakan yaitu model waterfall (Pressman, 2008). Waterfall merupakan model klasik yang sederhana dengan aliran sistem yang linier. Output dari setiap tahap merupakan input bagi tahap berikutnya. Alasan pemilihan model pengembangan waterfall karena model pengembangan waterfall sesuai dengan karakteristik pengembangan ini. Pengembangan ini merupakan pengembangan skala kecil yang diidentifikasi dari kemungkinan terjadinya perubahan kebutuhan dalam penelitian selama pengembangan perangkat lunak kecil. Tahap-tahap dalam pengembangan aplikasi mobile augmented reality menggunakan model waterfall dapat dilihat pada Gambar 2.

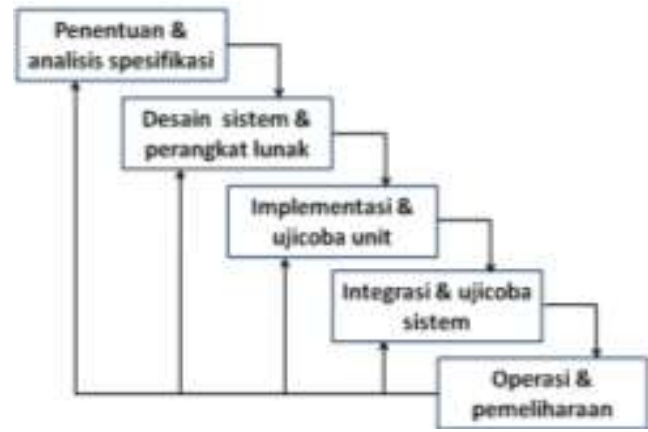

Gambar 2. Model pengembangan waterfall

Tahapan-tahapan dalam pengembangan aplikasi mobile augmented reality menggunakan model waterfall pada penelitian ini adalah sebagai berikut.

\subsection{Penentuan dan Analisis Spesifikasi-}

Pada tahap ini penentuan spesifikasi perangkat lunak didasarkan pada kebutuhan pengguna yaitu siswa SMA. Cara yang dilakukan adalah dengan melakukan observasi dan wawancara terhadap siswa mengenai apa saja yang menjadi kebutuhan belajar pada pelajaran biologi materi sel. Selain itu dilakukan juga analisis materi pelajaran sesuai dengan standar yang ada di sekolah.

\subsection{Desain Sistem dan Perangkat Lunak}

Pada tahap ini kegiatan yang dilakukan yaitu mendesain storyboard media pembelajaran yang akan dikembangkan. Storyboard merupakan visualisasi ide dari aplikasi yang akan dibangun, sehingga dapat memberikan gambaran dari aplikasi yang akan dihasilkan. Storyboard ini berisikan peta materi dan gambar rancangan desain perangkat lunak yang dikembangkan.

\subsection{Implementasi dan Uji Coba Unit}

Pada tahap ini dilakukan penulisan (pengkodean) program menggunakan bahasa pemrograman HTML, CSS, dan Javascript dengan bantuan editor notepad++ untuk materi berupa halaman web yang dinamis setelah itu kode program akan dikonversi menjadi halaman aplikasi mobile menggunakan library Phonegap. Sedangkan untuk fitur augmented reality menggunakan plugin Wikitude yang merupakan pengembangan dari FLARToolkit yang biasa digunakan untuk library augmented reality berbasis Flash.

\subsection{Integrasi dan Uji Coba Sistem}

Pada tahap pengujian akan dilakukan uji coba hasil pengkodean program menggunakan perangkat mobile berbasis android dengan versi minimal 4.4.4 (Lolipop). Perangkat mobile harus memiliki kamera agar fitur augmented reality dapat digunakan secara maksimal.

\subsection{Operasi dan Pemeliharaan}

Pada tahapan ini memungkinkan sebuah perangkat lunak mengalami perubahan ketika sudah digunakan pengguna. Perubahan dapat terjadi karena adanya kesalahan yang muncul dan tidak terdeteksi saat pengujian. Pemeliharaan dapat mengulangi proses pengembangan, tapi tidak untuk membuat perangkat lunak baru.

\section{HASIL DAN PEMBAHASAN}

Bagian ini membahas tentang hasil pengembangan aplikasi media pembelajaran mobile augmented reality beserta hasil uji coba lapangan yang dilakukan oleh pengguna.

\subsection{Hasil Pengembangan Media}

Penelitian ini menghasilkan aplikasi media pembelajaran mobile dan terdapat fitur augmented reality dengan materi bahasan sel. Gambar 3 menunjukkan halaman utama media pembelajaran yang berbentuk peta konsep materi. Bentuk peta materi ini memberikan gambaran siswa mengenai materi apa saja yang bisa dipelajari. Konsep materi dimulai dari pembahasan yang umum dan mengerucut ke konsep materi yang lebih spesifik.

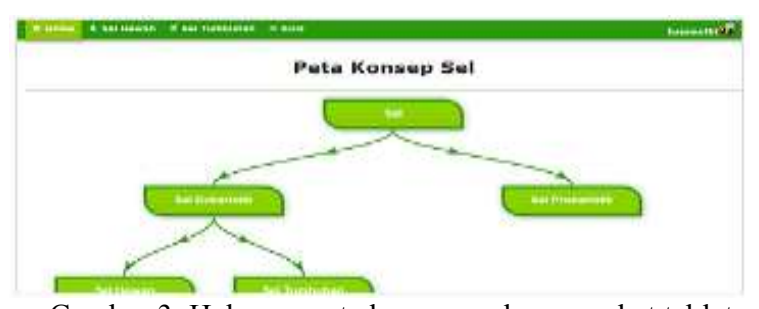

Gambar 3. Halaman peta konsep pada perangkat tablet

Gambar 4 menunjukkan halaman materi media pembelajaran yang berisi kombinasi gambar dan tulisan juga tombol navigasi menu untuk menuju materi yang lain.

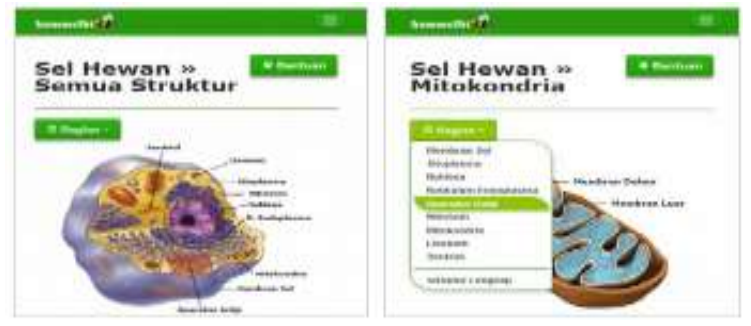

Gambar 4. Halaman materi dan menu 
Gambar 5. menunjukkan fitur andalan dari media pembelajaran ini yaitu augmented reality. Fitur ini memiliki keunggulan yaitu mampu memodelkan gambar 2D pada halaman materi menjadi 3D yang dapat dilihat pada dunia nyata melaui kamera sehingga dalam materi sel, fitur ini dapat menggantikan peran mikroskop. Cara penggunaannya adalah dengan mengarahkan kamera handphone ke marker sehingga objek 3D dapat terlihat pada layar.

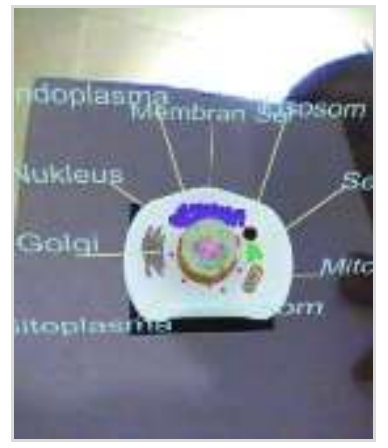

Gambar 5. Halaman Fitur Augmented Reality

\subsection{Kriteria Penilaian}

Terdapat 3 aspek penilaian aplikasi mobile augmented reality ini yaitu Aspek Perangkat Lunak, Aspek Desain Pembelajaran, dan Aspek Komunikasi Visual. Instrumen kevalidan media menggunakan skala likert dengan 4 alternatif jawaban, agar diperoleh data kuantitatif maka setiap alternatif jawaban diberi skor yaitu Sangat Setuju = 4, Setuju $=3$, Tidak Setuju $=2$, dan Sangat Tidak Setuju $=1$. Perhitungan persentase validitas menggunakan Rumus (1). berikut (Akbar dan Sriwiyana, 2010).

$$
V=\frac{T S E V}{S M A X} \times 100 \%
$$

Dimana V adalah persentase validitas, TSEV adalah total skor empirik validator, dan SMAX adalah skor maksimal yang diharapkan.

Perumusan kevalidan penilaian media dihitung menggunakan persentase yang dikemukakan oleh Akbar dan Sriwiyana (2010). Tabel 1. menunjukan kriteria kevalidan media pembelajaran.

Tabel 1. Kriteria Kevalidan Media Pembelajaran

\begin{tabular}{|c|c|c|}
\hline No & Kriteria & Tingkat Validitas \\
\hline 1 & $75,01 \%-100,00 \%$ & $\begin{array}{c}\text { Sangat Valid } \\
\text { (dapat digunakan tanpa revisi) }\end{array}$ \\
\hline 2 & $50,01 \%-75,00 \%$ & $\begin{array}{c}\text { Cukup Valid } \\
\text { (dapat digunakan dengan revisi) }\end{array}$ \\
\hline 3 & $25.01 \%-50.00 \%$ & $\begin{array}{c}\text { Tidak Valid } \\
\text { (tidak dapat digunakan) }\end{array}$ \\
\hline 4 & $00.00 \%-25.00 \%$ & $\begin{array}{c}\text { Sangat Tidak Valid } \\
\text { (terlarang digunakan) }\end{array}$ \\
\hline
\end{tabular}

\subsection{Hasil Uji Coba}

Uji Coba media pembelajaran dilakukan dengan menggunakan angket yang disebarkan kepada 28 siswa SMA sebagai pengguna. Hasil uji coba disajikan pada Tabel 2.

Tabel 2. Hasil Uji Coba Media Pembelajaran

\begin{tabular}{|c|c|c|c|c|}
\hline No & Aspek Penilaian & $\sum$ TSEV & $\sum$ SMAX & $\mathbf{V}$ \\
\hline 1. & $\begin{array}{l}\text { Perangkat Lunak } \\
\text { Media mudah } \\
\text { dioperasikan/digunakan }\end{array}$ & 100 & 112 & 89,3 \\
\hline 2. & $\begin{array}{l}\text { Desain Pembelajaran } \\
\text { Materi pembelajaran pada } \\
\text { media jelas dan mudah } \\
\text { dipahami }\end{array}$ & 99 & 112 & 88,4 \\
\hline 3. & $\begin{array}{l}\text { Soal evaluasi yang } \\
\text { disajikan mudah dipahami }\end{array}$ & 96 & 112 & 85,7 \\
\hline 4. & $\begin{array}{l}\text { Media menyediakan } \\
\text { layanan/fitur untuk } \\
\text { berinteraksi dengan } \\
\text { pengguna }\end{array}$ & 97 & 112 & 86,6 \\
\hline 5. & $\begin{array}{l}\text { Media dapat digunakan di } \\
\text { luar pembelajaran di kelas }\end{array}$ & 104 & 112 & 92,9 \\
\hline 6. & $\begin{array}{l}\text { Media dapat memotivasi } \\
\text { belajar }\end{array}$ & 101 & 112 & 90,2 \\
\hline 7. & $\begin{array}{l}\text { Komunikasi Visual } \\
\text { Bahasa yang digunakan } \\
\text { pada media komunikatif } \\
\text { dan mudah dimengerti }\end{array}$ & 103 & 112 & 92 \\
\hline 8. & $\begin{array}{l}\text { Gambar media terlihat } \\
\text { jelas dan mudah dipahami }\end{array}$ & 108 & 112 & 96,4 \\
\hline 9. & $\begin{array}{l}\text { Tulisan pada media } \\
\text { mudah dibaca }\end{array}$ & 102 & 112 & 91,1 \\
\hline 10. & $\begin{array}{l}\text { Desain antarmuka media } \\
\text { disajikan secara menarik }\end{array}$ & 109 & 112 & 97,3 \\
\hline & Jumlah & 1019 & 1120 & 91,0 \\
\hline
\end{tabular}

Data hasil uji coba dianalisis mengacu pada kriteria penilaian Akbar dan Sriwiyana (2010) tentang kriteria validitas analisis persentase. Dari segi perangkat lunak, butir-butir item yang telah dinilai siswa diperoleh hasil dengan persentase $89,3 \%$ dan dikategorikan pada kriteria sangat valid dan tidak perlu direvisi. Dari segi desain pembelajaran, butirbutir item yang telah dinilai siswa di-peroleh hasil dengan persentase antara $85 \% \quad-\quad 93 \%$ dan dikategorikan pada kriteria sangat valid dan tidak perlu direvisi. Dari segi komunikasi visual, butir-butir item yang telah dinilai siswa diperoleh hasil dengan persentase antara 91\% - 98\% dan dikategorikan pada kriteria sangat valid dan tidak perlu direvisi. Kesimpulan skor total keseluruhan yang diperoleh dari uji coba dinyatakan valid dari hasil persentase sebesar 91\% dikategorikan sangat valid dan tidak perlu direvisi.

\section{KESIMPULAN}

Produk yang dihasilkan dalam penelitian ini berupa aplikasi media pembelajaran berbasis mobile dengan fitur augmented reality pada pokok bahasan sel. Produk dikembangkan dengan metode pengembangan aplikasi Waterfall. Media pembelajaran mobile ini memadukan unsur multimedia, pengemasan fitur materi tentunya tidak hanya berisikan teks tetapi juga dilengkapi dengan ilustrasi gambar dan fitur augmented reality supaya memudahkan siswa dalam memahami materi.

Hasil uji coba kepada siswa menunjukkan 
bahwa media pembelajaran yang dikembangkan berdasarkan dari perhitungan angket dan kriteria penilaian dari Akbar dan Sriwiyana (2010) menunjukkan bahwa media yang digunakan sangat valid dan tidak perlu direvisi. Dengan demikian, aplikasi mobile augmented reality sebagai media pembelajaran pada pokok bahasan sel untuk siswa SMA kelas sudah dinyatakan valid dan layak digunakan.

\section{DAFTAR PUSTAKA}

Akbar, Sa'dun dan Hadi Sriwiyana. 2010. Pengembangan Kurikulum dan Pembelajaran Ilmu Pengetahuan Sosial (IPS). Yogyakarta: Cipta Media.

Arief S. Sadiman, et al. 2009. Media pendidikan: pengertian, pengembangan dan pemanfaatan-nya. Jakarta: PT. Raja Grafindo Persada.

Arsyad, Azhar. 2009. Media Pembelajaran. Jakarta: PT. Raja Grafindo Persada.

Billinghurst, Mark. 2002. Augmented Reality in Education. (Online), (http://it.civil.aau.dk/it/ education/reports/ar_edu.pdf).

Kaufman, Hannes. 2001. Collaborative Augmented Reality in Education. (Online), (http:// citeseerx.ist.psu.edu/viewdoc/download?doi= 10.1.1.12.2215\&rep=rep1\&type $=$ pdf).

Pressman, R.S. 2008. Software Engineering: $A$ Practitioner's Approach Seventh Edition. New York: McGrawHill.

Ronald T. Azuma. 1997. A Survey of Augmented Reality. Malibu: Hughes Research Laboratories.

Sugiyono. 2009. Metode Penelitian Kuantitatif Kualitatif dan $R \& D$. Bandung: Alfabeta.

\section{Biodata Penulis}

Julian Sahertian, memperoleh gelar Sarjana Pendidikan (S.Pd), Jurusan Pendidikan Teknik Informatika Universitas Negeri Malang, lulus tahun 2012. Memperoleh gelar Magister Teknik (M.T) Program Pasca Sarjana Magister Informatika Institut Teknologi Bandung, lulus tahun 2016. Saat ini menjadi Dosen di Universitas Nusantara PGRI Kediri.

Risa Helilintar, memperoleh gelar Sarjana Komputer (S.Kom), Jurusan Teknik Informatika Universitas Nusantara PGRI Kediri, lulus tahun 2011. Memperoleh gelar Magister Komputer (M.Kom) Program Pasca Sarjana di Universitas Amikom, lulus tahun 2015. Saat ini menjadi Dosen di Universitas Nusantara PGRI Kediri. 